http://jmscr.igmpublication.org/home/ ISSN (e)-2347-176x ISSN (p) 2455-0450

crossref DOI: https://dx.doi.org/10.18535/jmscr/v7i11.07

Journal Of Medical Science And Clinical Research

\title{
Study of serum Aminotransfersase levels in dengue fever and its correlation
}

\author{
Authors \\ Dr Balakumar.J' ${ }^{1}$, Prof. Dr S. Balasubramaniyan.M.D²., Dr N.Paari M.D. ${ }^{3}$ \\ ${ }^{1}$ Post Graduate, Department of General Medicine, Rajah Muthiah Medical College \& Hospital, \\ Annamalai University, Chidambaram, India - 608002 \\ ${ }^{2}$ Professor, Department of General Medicine, Rajah Muthiah Medical College \& Hospital, \\ Annamalai University, Chidambaram, India - 608002 \\ ${ }^{3}$ Assistant Professor, Department of General Medicine, Rajah Muthiah Medical College \& Hospital, \\ Annamalai University, Chidambaram, India - 608002
}

\begin{abstract}
Background: Dengue fever is the most prevalent arthropod borne viral illness in humans caused by dengue virus. The involvement of liver in dengue fever is not uncommon. Liver involvement in dengue fever is manifested by the elevation of transaminases due to direct attack of virus itself or the use of hepatotoxic drugs. ${ }^{\text {l. }}$
\end{abstract}

Aim and Objective: to assess the serum aminotransferase level in patient with dengue fever and to correlate serum aminotransferase level and severity of dengue fever.

Methods: This is a prospective observational study conducted from November 2017 to October 2019. A total of 50 fever patients admitted with positive dengue serology in Medicial ward, RMMCH were included after satisfying the inclusion and exclusion criteria. All the patients were subjected to complete history taking and clinical examination. Investigations like complete blood count, liver function test, dengue serology and abdominal ultrasound were done in all patients.

Result: A total of 50 dengue serology positive patient were included in the study. Among them there were $27(54 \%)$ males and 24(46\%) females. In our study 41 patients (82\%) had elevated serum transaminase level, Mean AST level was 134.84 IU/L and the mean ALT level was 107.88 IU/L. The level of AST is higher when compared to ALT in most of the patients. Among those who had elevated aminotransferase level 12 patients (24\%) had both elevated aminotransferase level and free fluid in the abdomen. Out of 50 patients 32 (64\%) had reduced platelet count (less than one lakh) and all the 32 patients had elevated serum aminotransferase level. There was significant negative correlation between serum aminotransferase level and platelet count (P value <0.001)

Conclusion: Hepatic dysfunction is very common in all forms of Dengue infection. Serum Aminotransferase level correlate with severity of Dengue fever. Aspartate Aminotransferase was significantly raised when compared to Alanine Aminotransferase in most of the patients.

Keywords: Dengue fever, Serum Aminotransferase, Aspartate Aminotransferase.

\section{Introduction}

Dengue infection an arthropod -borne viral haemorrhagic fever, continues to be a major challenge in public health, especially in India.
Dengue fever is one of the world's most common viral heamorrhagic fever, most geographically wide spread among the arthropod borne viral illness, caused by Arbovirus of Flavivirus family 
with 4 serotypes. It is transmitted by Aedes aegypti and Aedes albopticus. Four spectra of illness are seen - an asymptomatic phase, acute febrile phase, classical Dengue fever, Dengue hemorrhagic fever (DHF) including Dengue shock syndrome (DSS). Dengue viral infection has been recognized as one of the most important and worlds biggest emerging epidemics. ${ }^{2}$

Hepatic involvement can be characterized by acute hepatitis with pain in the right hypochondrium, hepatomegaly, jaundice and raised aminotransferase level. In hepatitis the level of these enzyme reach a maximum on the ninth day after the onset of symptoms and they gradually return to normal levels within three weeks. Histopathological findings includes centrilobular necrosis, fatty changes (microvesicular), hyperplasia of the kupffer cells, acidophil bodies and monocytes infiltration of portal tract. In most cases hepatic involvement prolongs the clinical course of self-limiting viral infection. The spectrum of involvement include asymptomatic elevation of serum aminotransferase to occurrence of severe manifestation in the form of liver failure. ${ }^{3}$

\section{Aims and Objective}

1. To assess the serum aminotansferase level in patients with dengue fever

2. To correlate serum aminotransferase level and severity of dengue fever

\section{Inclusion Criteria}

- Fever patients admitted with dengue serology positive - IgM / NS1

\section{Exclusion Criteria}

- History of alcohol abuse

- Chronic liver disease

- History of intake of hepatotoxic drugs.

\section{Methods}

This is a prospective observational study conducted from November 2017 to October 2019. A total of 50 fever patients admitted with positive dengue serology in Medical ward, RMMCH were included after satisfying the inclusion and exclusion criteria. All the patients were subjected to complete history taking and clinical examination. Investigations like complete blood count, liver function test, dengue serology and abdominal ultrasound were done in all patients.

\section{Results}

Table 1: Descriptive analysis of age group in study population $(\mathrm{N}=50)$

\begin{tabular}{|l|c|c|}
\hline Age group & Frequency & Percentage \\
\hline 15 to 25 & 17 & $34 \%$ \\
\hline 26 to 35 & 11 & $22 \%$ \\
\hline 36 to 45 & 8 & $16 \%$ \\
\hline 46 to 55 & 9 & $18 \%$ \\
\hline 56 to 65 & 3 & $6 \%$ \\
\hline$>65$ & 2 & $4 \%$ \\
\hline Total & 50 & $100 \%$ \\
\hline
\end{tabular}

Figure 1: Bar chart of age distribution in study population $(\mathrm{N}=50)$

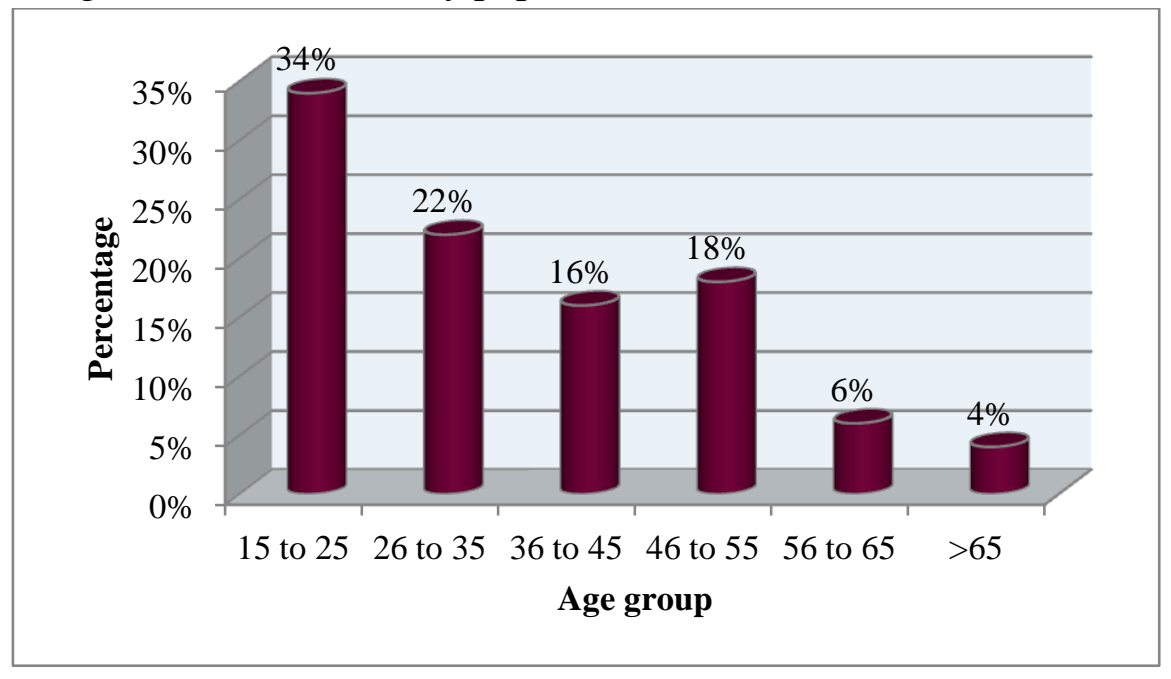




\section{JMSCR Vol||07||Issue ||11||Page 36-41||November}

Table 2: Descriptive analysis of gender in study population $(\mathrm{N}=50)$

\begin{tabular}{|l|c|c|}
\hline Gender & Frequency & Percentage \\
\hline Male & 27 & $54 \%$ \\
\hline Female & 23 & $46 \%$ \\
\hline Total & 50 & $100 \%$ \\
\hline
\end{tabular}

Figure 2: Pie chart of gender distribution in study population $(\mathrm{N}=50)$

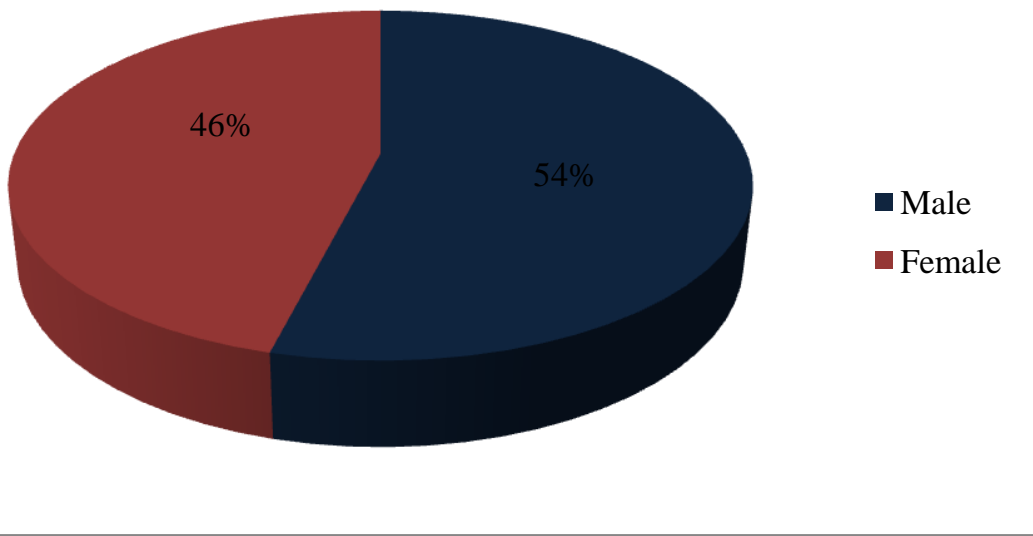

Table 3: Comparison of mean AST among patient with and without ascites $(\mathrm{N}=50)$

\begin{tabular}{|l|c|c|c|}
\hline \multirow{2}{*}{ Parameter } & \multicolumn{2}{|c|}{ FREE FLUID } & Unpaired t test \\
\cline { 2 - 3 } & F value
\end{tabular}

Figure 3: Bar chart of comparison of mean AST among patient with and without ascites $(\mathrm{N}=50)$

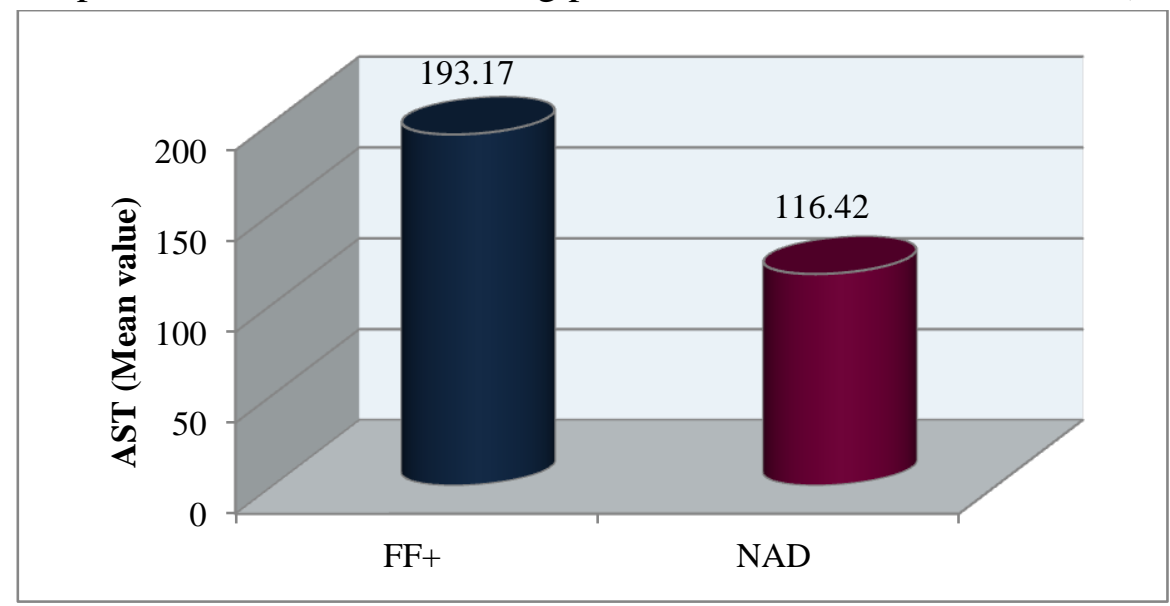

Table 4: Comparison of mean ALT among patient with and without ascites $(\mathrm{N}=50)$

\begin{tabular}{|c|c|c|c|}
\hline \multirow{2}{*}{ Parameter } & \multicolumn{2}{|c|}{ FREE FLUID } & \multirow{2}{*}{$\begin{array}{c}\text { Unpaired } t \text { test } \\
\quad \text { P value }\end{array}$} \\
\hline & $\mathrm{FF}+(\mathrm{N}=12)$ & NAD $(\mathbf{N}=38)$ & \\
\hline $\begin{array}{l}\text { ALT } \\
(\text { Mean } \pm \mathrm{SD})\end{array}$ & $146.58 \pm 77.90$ & $95.66 \pm 76.35$ & 0.051 \\
\hline
\end{tabular}




\section{JMSCR Vol||07||Issue |11||Page 36-41||November}

Figure 4: Bar chart of comparison of mean ALT among patient with and without ascites $(\mathrm{N}=50)$

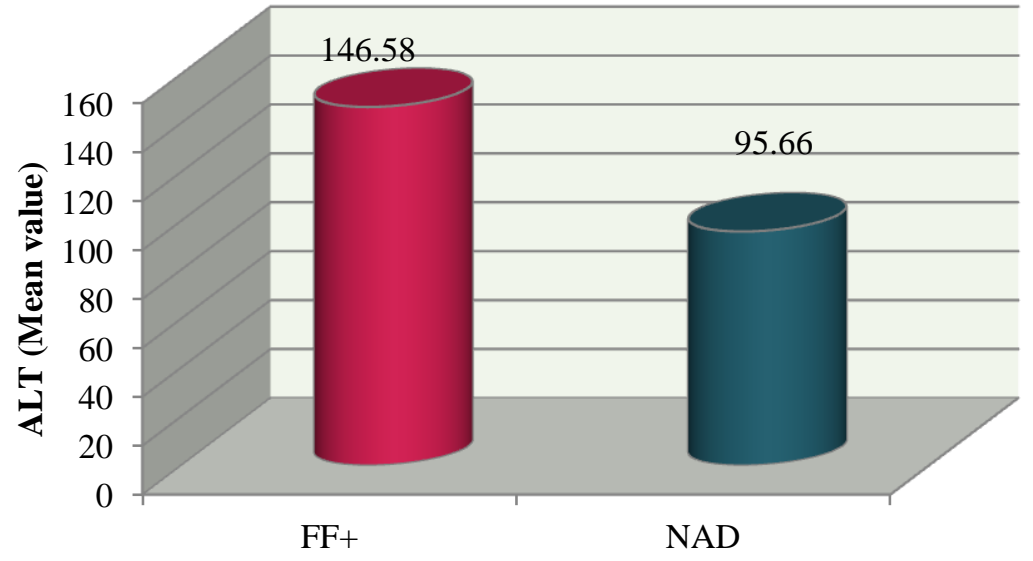

Table 5: Correlation between Platelets count and AST level $(\mathrm{N}=50)$

\begin{tabular}{|l|c|c|}
\hline Parameter & Pearson correlation & P value \\
\hline AST (IU/L) & -0.447 & 0.001 \\
\hline
\end{tabular}

There was a weak negative correlation between platelets count $/ \mathrm{mm} 3$ and AST (IU/L) ( $\mathrm{r}$ value: -0.452 , $\mathrm{P}<0.001)$

Figure 5: Scatter plot diagram of correlation between Platelets count and AST level (N=50)

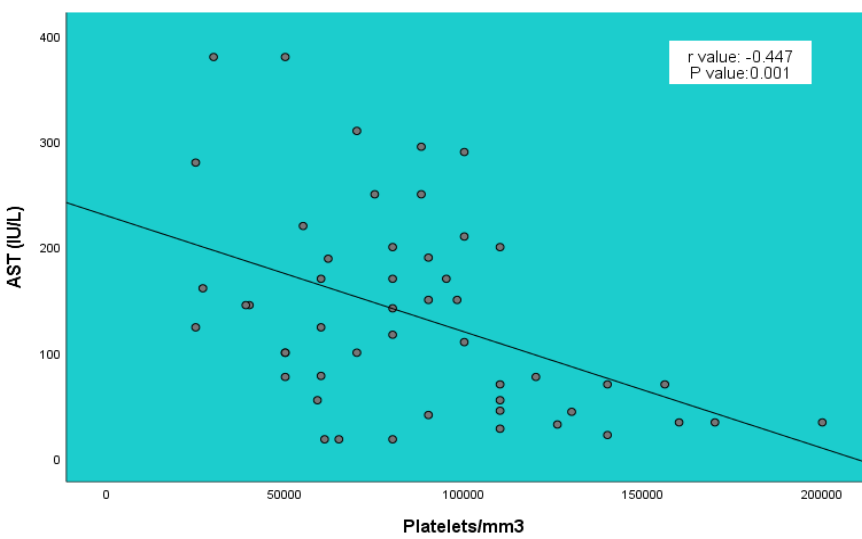

Table 6: Mean valve of serum aminotransferase level in liver enzyme elevated patients

\begin{tabular}{|l|c|}
\hline Mean & Value \\
\hline AST High & 134.84 \\
\hline ALT High & 107.88 \\
\hline
\end{tabular}

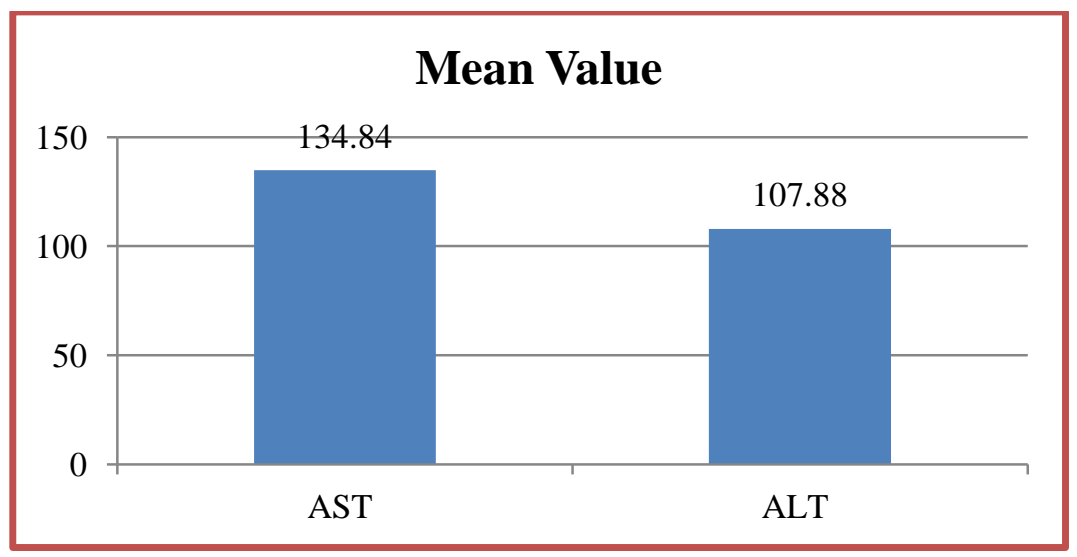


Results

- In this study, 50 dengue serology positive patients were studied.

- Out of 50 patient 27(54\%) were male and $23(46 \%)$ were female.

- Most of the patient were in the age group of 15-25 years (34\%) and mean age of the patient was $35.94 \pm 15$.

- All the patient had fever as a presenting complaint. Most of them had myalgia at the time of presentation.

- In our study 41 patients (82\%) had elevated serum transminases level.

- Mean AST level was 134.84 IU/L and the mean ALT level was 107.88 IU/L.

- The incidence of free fluid in abdomen is more among patients with elevated serum aminotransferase level when compared to those who had normal enzyme level.

- Among those who had elevated aminotransferase level 12 patients (24\%) had free fluid in the abdomen.

- Among those patients who had normal aminotransferase level no one had free fluid in the abdomen.

- There was significant correlation between serum aminotransferase level and free fluid in the abdomen.

- Out of 50 patients 32 (64\%) had reduced platelet count (less than one lakh) and all the 32 patients had elevated serum aminotransferase level.

- There was significant negative correlation between serum aminotransferase level and platelet count $(\mathrm{P}$ value $<0.001)$

\section{Discussion}

- Hepatic involvement in dengue is manifested by hepatomegaly clinically or increase in liver enzymes biochemically. It is either due to direct viral toxicity or dysregulated immunologic injury in response to virus. ${ }^{3}$

- In our study special attention was put on change in the serum transaminase levels among dengue patients. There was presence of hepatic dysfunction in most of our patients as evidenced by increased level of serum transaminases in $41(82 \%)$ patients.

- Similar results were found in the study conducted by Srivenu Itha et al where 97\% had hepatic involvement with raised liver enzymes. $^{4}$

- Arun Sedhain et al found that USG abdomen findings includes hepatomegaly, Gall bladder thickening and third space loss. They were higher significantly in DHF as compared to DF patients. ${ }^{5}$

- In our study also the incidence of free fluid in abdomen is more among patients with elevated serum aminotransferase level which indicates the severity of Dengue fever.

- Rajni R. shivkar et al in their study concluded that transaminase levels increase in almost all dengue patients. The rise in AST and ALT level increases with increase in dengue severity which is indicated by fall in platelet count as they are negatively correlated with each other. ${ }^{6}$ In our study also 32 patients had reduced platelet count (less than one lakh) and all the 32 patients had elevated serum aminotransferase level which indicates the increase in severity.

\section{Conclusion}

Hepatic dysfunction is very common in all forms of Dengue infection. Serum Aminotransferase level has directly proportional correlation with severity of dengue fever. Aspartate aminotransferase was significantly raised when compared to Alanine aminotransferase in most of the patients.

Therefore, use of liver function test to evaluate the degree of liver damage is of great importance and markers such as Aspartate aminotransferase and Alanine aminotransferase may be used as parameters to evaluate severity. 


\section{Reference}

1. Murlidhar, Sarveshwar Sharan Dadhich, Mangesh Borkar, Sanjiv Maheshwari, Monika Maheshwari, Yad Ram Yada; The Study of Serum Aminotransferase Levels in Dengue Fever and it's Correlation with Clinical Profile ; "The Antiseptic" Vol. 113 No. 8 \& P : 8 - 12; august 2016

2 Jnaneshwari M, Jayakumar S, Arun Kumar, Uday G. "Study of Serum Aminotransferase Levels in Dengue Fever". Journal of Evolution of Medical and Dental Sciences 2014; Vol. 3, Issue 10, March 10; Page: 2445-2455, DOI: 10.14260/jemds/2014/2157

3 Samanta J, Sharma V. Dengue and its effects on liver. World J Clin Cases 2015; 3(2): 125-131 Available from: URL: http:// www.wjgnet.com/2307-

8960/full/v3/i2/125.htm DOI: http:// dx.doi.org/10.12998/wjcc.v3.i2.125

4 Srivenu Itha, Rajesh Kashyap, Narendra Krishnani, Vivek A. Saraswat, Gourdas Choudhuri, Rakesh Aggarwal; Profile of liver involvement in dengue virus infection; Natl Med J India 2005;18:12730

5 Arun Sedhain, Gandhi R Bhattarai, Shital Adhikari, Barun Shrestha, Abja Sapkota. Liver Involvement Associated with Dengue Infection During A Major Outbreak in Central Nepal. Journal of Advances in Internal Medicine 2013;02(02):42-6.

6 Rajni R. Shivkar, Meghana K. Padwal, Akanksha Vaidya; Correlation of Liver Transaminases with Platelet count in Dengue patients from Tertiary Care Hospital in Western India; Int J Cur Res Rev | Vol 10; Issue 5: March 2018. 